\title{
LA POLITICA Y LO POLITICO: DEL DILEMA AL PROBLEMA. Análisis de las argumentaciones y propuestas de acción de jóvenes estudiantes de la Ciudad de Buenos Aires*
}

\author{
Miriam Kriger $^{* *}$
}

\section{Resumen}

El artículo presenta hallazgos de un estudio realizado en Buenos Aires y Conurbano sobre las representaciones de "la política" y "lo político" de jóvenes estudiantes. Tomando como punto de partida el antagonismo hallado entre ellas en el contexto posterior a la crisis del 2001, proponemos indagar si en la actualidad se ha producido una re articulación ligada a una mayor politización. Se analizan los argumentos surgidos de la discusión grupal en torno al planteo de un dilema moral, enfatizando en los sentidos, valoraciones, posicionamientos y actitudes hacia la política como concepto ideal y práctica situada. Encontramos mayor confianza en la "'política'" como herramienta de construcción social, a la vez que persiste una concesión antipolítica fundada en la desconfianza hacia los políticos y las prácticas facciosas. Finalmente, se muestra que cuando el dilema es problematizado reflexivamente, se accede a un mayor pensamiento político y comprensión de los vínculos entre ciudadanía y clase política.

\section{Palabras clave}

Política - Político - Jóvenes.

\footnotetext{
* Se agradece el aval del Proyecto PICT 212-2751 dirigido por la Dra. Miriam Kriger.

** La Doctora Miriam Kriger es Investigadora Adjunta del CONICET-CIS-IDES, docente investigadora de la Facultad de Ciencias Sociales (UBA).

Correo electrónico: mkriger@gmail.com
} 


\section{Abstract}

The paper reports the results of a research project methodology combined reached more than 3,500 young people in the city of Salta, Argentina, conducted between 2009 and 2013. The research is based at the Research Council of the University Nacional de Salta.

With qualitative and quantitative methodology imaginary constructions aged 15 and 29 years for political practices in areas such as political parties, schools, unions addressed; and visions of the subjects about politics, social change and the future. Comparative data were processed Constant Method and quantitative information for descriptive statistics was applied. The results show a range of meanings on politics, while unveil a political nature that challenges the instituted in pursuit of collective well-being.

\section{Keywords}

Youth - politics - participation/commitment.

\section{1- Presentación:}

En el presente artículo nos proponemos contribuir a la comprensión del vínculo entre juventud y política en contextos contemporáneos, en un momento de irrupción de los jóvenes en lo social (Kriger, 2013) que habilita muy diversas lecturas: del 'encantamiento de lo público' (Aguilera, 2011) a la 'consagración de la juventud como causa militante' (Vázquez, 2013), de la re-politización de los jóvenes en el marco de una 'epistemología de la esperanza' (Saintout, 2013) a la 'tercera invención' en clave de juventud renacionalizada (Kriger 2014). En la Argentina, esto adquiere una fuerza notable en contraste con la supuesta y polémica despolitización de los jóvenes entre la década de 90 y el comienzo del nuevo milenio, sostenida por un discurso hegemónico que describía sus prácticas como 'atomizadas y apáticas en términos políticos' (Kropff \& Núñez, 2009), negativizándolas (Chaves, 2009). En dirección contraria, en los últimos años se ha producido un cambio en la visibilización y la interpelación de los jóvenes (Kriger y Daiban, 2015) y en la construcción de su figura social y jurídica, ${ }^{1}$ así como una inversión moral del significado y la valoración de la política: si antes ella era "mala" y

\footnotetext{
${ }^{1}$ Como ejemplo, en el 2012 se promulgó la ley 26774/12 que adelantó el voto a los 16 años de edad.
} 
destructiva, ahora es "buena" y constructiva, sin que tengamos elementos para afirmar que ello implique per se un cambio sustancial en sus significados profundos ni en la capacidad para convivir con el desacuerdo en que se funda (Rancière, 1996).

De modo que, precisamente cuando el discurso social y sus múltiples agendas parecen convertir a la política en un imperativo para los jóvenes de este tiempo, creemos que la aseveración de que se han politizado requiere ser estudiada y complejizada, tanto desde una mirada histórico-antropológica que enmarque la figura del joven y la categoría de juventud en contextos situados (véase al respecto: Kriger, 2014), como desde una perspectiva psico-sociocultural que permita construir categorías y dimensiones para su investigación empírica y problematización teórica. Desde esta última perspectiva hemos realizado diversos trabajos referidos a la construcción de la identidad en acción y el involucramiento a través de los afectos, la comprensión cognitiva y los valores (Fernández-Cid, Kriger \& Rosa, 2014; Kriger \& Fernández-Cid, 2011, 2013, 2014), y a indagar el pasaje de la despolitización a la politización como proceso (Kriger, 2013; Kriger y Bruno, 2013; Kriger y Fernández Cid, 2012; Kriger y Dukuen 2012 y 2014; Kriger y Daiban, 2015; Kriger y Said, 2015), convencidos de que ninguno de los dos marca un punto de llegada, sino un horizonte conceptual en virtud del cual se disponen las complejas y reflexivas dinámicas en que se construye el vínculo de los jóvenes con la sociedad.

Definimos así a la politización como un proceso psico-sociocultural complejo, de carácter intra- e intersubjetivo, en que se resignifica y reactualiza permanentemente la vida colectiva, en lo que históricamente se instituyó desde la modernidad como proyecto común o nación en tanto 'comunidad imaginada' (Anderson, 1983). En este punto, es fecundo distinguir entre lo político y la política siguiendo a Lefort (1992), dado que es en el juego entre ellos donde la dinámica social se activa. Mientras que el primer término designa

... un momento de ruptura y renovación del orden social, de radical contingencia, donde se muestran las alternativas posibles y desaparece cualquier interpretación de necesidad histórica, que no necesariamente se tiene que expresar en procesos revolucionarios o grandes cambios sociales, sino también en hechos de carácter menos radical (Muñoz, 2004: 23);

el segundo (la política) es: "el lugar donde se ha normalizado lo político, es decir: el espacio donde se recrean los intercambios institucionalizados del conflicto, donde se oculta la contingencia radical del orden y se tratan de domesticar las diferencias" (óp.cit). De modo tal que la política es el mundo de la historia, pero es también la plataforma para la irrupción de lo político, la resignificación de los significados previos y de los contextos, de donde sigue aflorando el siempre viejo/nuevo mundo común.

En vistas a estudiar empíricamente los procesos de politización de los jóvenes en la Argentina contemporánea, tomamos como punto de partida el fuerte distanciamiento 
hallado en estudios previos (Kriger, 2007) entre las representaciones altamente positivas de la ciudadanía (que encarnaba lo político) y las totalmente negativas de la política (encarnada por un Estado ausentado y una clase política corrupta) que en su momento caracterizamos como "dialéctica de enemigos íntimos" (Kriger, 2010: 16). Esta nos pareció sintomática del estallido del $2001^{2}$ en tanto divorcio efectivo de los ciudadanos y la clase política, que dio lugar a una concepción antipolítica singular, que "no era lo contrario de la política, sino simplemente su imagen invertida: una manera de hacer política contraponiéndose exactamente a ella" (Espósito, 1988: 12). Lo cual también coincide en gran medida con lo que Rosanvallon (2006) ha caracterizado a nivel global como 'contrademocracia' en referencia a un ejercicio democrático no institucionalizado y reactivo, que expresa de modo directo las expectativas y decepciones de la sociedad y el rol vigilante de los ciudadanos.

En tal esquema, la ciudadanía era pensada idealmente por los jóvenes como una dimensión no política de lo social aunque protagonizaran lo político (por ejemplo: "el argentinazo"); pero el problema era que si la ciudadanía y los ciudadanos aparecían para ellos como custodios morales de la democracia y del proyecto común, no solo contra los políticos, sino contra la política integralmente ("porque mancha todo"): ¿cómo harían ellos para participar de tal proyecto, prescindiendo de la herramienta necesaria, que es justamente la política? En el proceso de salida de la crisis, particularmente a partir del 2003 con el gobierno de Néstor Kirchner, se produjeron diversas estrategias ligadas en lo simbólico a la "reconstrucción nacional en clave refundacional" (Kriger, 2010:17) y en lo material a la "rearticulación de la institucionalidad estatal" (Aguiló \& Wahren, 2012: 2) juntamente con la recreación de una "una gramática movimientista" (Peréz \& Natalucci, 2012: 11) que logró absorber bajo un gran paraguas partidario a las organizaciones sociales y populares de todo el espectro ideológico. Durante la siguiente década, ya no entonces en el contexto inmediatamente posterior a la crisis, sino en una etapa de "consolidación conflictiva del proyecto-país" (Kriger, 2013) con una mayor legitimación de la política y una explícita recuperación del rol del Estado nacional, nos pareció importante volver a indagar estas tensiones.

Realizamos un nuevo estudio entre 2011 y 2013, y encontramos que tanto la creencia en la política como su valoración tendieron a ser positivas en términos relativos, restituyéndole legitimidad al reconocerla como herramienta clave de la democracia y distinguirla de los usos que pudieran darle los políticos. Sin embargo, ello no se traducía aún en un aumento proporcional de la disposición hacia la política, y menos

\footnotetext{
${ }^{2}$ Fue un momento de virtual acefalía política después de los sucesos que el 20 de diciembre de 2001 llevaron a la renuncia de De la Rúa. En los diez días siguientes, Argentina tuvo 3 presidentes que renunciaron -Puerta (21 al 22/12), Rodríguez Saá (22 al 29/12), Camaño (29/12 al 1/1/02)-y el 1 de enero del 2002 asumió el cargo Duhalde de modo provisional hasta las elecciones, luego de las cuales comenzó el gobierno de Néstor Kirchner.
} 
en la participación efectiva de los jóvenes (Kriger \& Bruno, 2013, Kriger y Fernández Cid, 2012). También notamos que predominaba la participación de tipo social sobre la propiamente política, con más presencia en movimientos sociales que en partidos políticos en todas las clases sociales y con acento en las populares (Kriger \& Dukuen, 2012). En suma: los hallazgos contrastaron con la percepción social de una extendida politización de los jóvenes, pero señalaron que íbamos en esa dirección.

Creemos que es crucial seguir profundizando en esta línea, investigando de qué modos y con qué dinámicas se pueden activar los nexos entre emociones, valores, conocimientos y posicionamientos que deriven en una praxis política. Ello resulta cada vez más relevante atentos a promover una educación política genuina, que habilite el pasaje de las representaciones individuales a la acción colectiva y a una creación política colectiva que supere la impronta refundacional y los riesgos asociados a una "hipertrofia identitaria" (Kriger, 2010) en clave de un nacionalismo romántico (Carretero, 2007).

Teniendo en cuenta este propósito, planificamos un nuevo abordaje cualitativo para ahondar el conocimiento acerca de las significaciones, valoraciones y actitudes en torno a la política y lo político, con la hipótesis conjetural de que las tensiones entre ellos deberían ser menores cuanto mayor o más intensa fuera la politización. Realizamos planteos grupales de una situación dilemática, tomando el modelo propuesto por Ruiz Silva (2009), que resulta muy apto para colocar a los participantes frente al conflicto, evitando que puedan conciliarlo ni eludirlo con facilidad, y para generar una deliberación donde lo moral, lo afectivo y lo intelectual se expresen como argumento y como posición. Entendemos a esta última en tanto "conglomerado de derechos, obligaciones y deberes disputables a corto plazo" (Harré, 2012: 193) que dispone a la acción, determinada a su vez por la virtud, concepto que para el mismo autor refiere a los atributos personales y/o sociales que le permiten a la persona actuar en cada situación específica y que es en última instancia "el valor encarnado en la identidad del sujeto" (Fernández Cid, 2013: 46).

A continuación, presentaremos el estudio y luego analizaremos algunos de los argumentos propuestos por los jóvenes que participaron del trabajo grupal en las escuelas. Es nuestro objetivo establecer relaciones entre los diversos planos en que los sujetos piensan/sienten la política y lo político, a través del análisis e interpretación de sus intervenciones en una discusión, considerando la argumentación desde un enfoque pragmático que la liga a la acción más que a la descripción (Castorina \& Faigenbaum, 2003), lo cual nos permite referirnos a un aspecto no solo representacional sino actitudinal, y como un elemento de la deliberación dialógica constitutiva del pensamiento político (Kriger, 2010).

El dilema utilizado -"El barrio espera una solución" (Siede, Helman \& Micó, 2001)trata sobre un conflicto que divide las posiciones entre una visión negativa de la política regida por prácticas facciosas y clientelares, y una visión positiva de lo político 
como práctica activa de la sociedad civil y sus organizaciones no partidarias. Dado que el antagonismo planteado no es neutral, sino tributario de la mirada antipolítica que se impuso en la década de 90 -como momento en que se produjo el debilitamiento (autogestionado por sus propias políticas) del Estado en su rol de 'instancia organizadora de las prácticas sociales' (Ortiz, 2002) que llevó a la desarticulación del estado-nacional (Milstein, 2009) y a la brecha más honda entre la política y lo políticoello le da un especial valor instrumental al dilema, ya que permite verificar distintos grados de vigencia de tal concepción y detectar los cambios al respecto y los núcleos duros subyacentes a los cambios políticos y sociales.

\section{El estudio}

Se presentan resultados parciales de una investigación más amplia sobre el vínculo de estudiantes argentinos con la política, la nación y la ciudadanía ${ }^{3}$ realizada en Buenos Aires y Conurbano entre 2011 y 2013, entre alumnos/as de 17 y 18 años ( $N=280)$ de siete escuelas de la Ciudad de Buenos Aires y Conurbano Bonaerense, de diversas clases sociales. En este artículo, solo haremos referencia a sus representaciones (valoraciones, significaciones, pensamientos), disposiciones y actitudes hacia la política en un sentido amplio, que integra las variables tensiones entre la política y lo político. Analizaremos fragmentos de las discusiones producidas a partir de la presentación de una situación dilemática realizada con dos grupos de 6 estudiantes de dos escuelas de la muestra (en total siete).

Tomamos la adaptación de Ruiz-Silva (2009) de la utilización del dilema moral por Kohlberg (1984), dado que, si bien esta metodología fue en su origen una herramienta pedagógica e investigativa clave para el enfoque constructivista del desarrollo moral, en este trabajo y siguiendo al primer autor, restringiremos su uso a la generación de argumentos y recursos deliberativos que permitan detectar y analizar las representaciones y actitudes de los participantes en torno a la política, y su relación con la construcción social de 'lo común'. Como señala Ruiz Silva: "un dilema adecuadamente formulado no tiene respuestas correctas e incorrectas, suele promover la toma de posición, cuestionar las respuestas preconcebidas, los estereotipos y en general, favorecer la expresión de argumentos" (Ruiz Silva, 2011: 38).

Nos preguntamos: ¿qué tipo de elecciones valorativas, qué posiciones y qué argumentos generan los jóvenes ante un cuestionamiento de la política que pone el foco en las dinámicas facciosas y clientelares y en el leitmotiv instalado desde los años 90, según el cual la corrupción es condición intrínseca e ineludible de toda acción y gestión política?

\footnotetext{
${ }^{3}$ Realizada en el marco del Proyecto PIP (CONICET) 11220100100307 ya finalizado y del Proyecto PICT 2012-2751 en curso, ambos bajo la dirección de la D. ${ }^{\text {a }}$ M. Kriger. La investigación más amplia a la que referimos se realizó en siete escuelas de la Ciudad de Buenos Aires y Conurbano, sobre un total de 280 estudiantes de 17 a 19 años de edad, de ambos géneros.
} 
A continuación, transcribimos literalmente el dilema que hemos trabajado con los estudiantes, tomado de Siede, Helman \& Micó (2001):

\section{El barrio espera una solución}

Rubén trabaja en una organización barrial que no responde a ninguna institución ni partido político. Él militó hace un tiempo en un partido, pero se cansó de las 'roscas' y los manejos turbios. Desde hace ya dos años, la agrupación barrial está tratando de conseguir que se construya una sala de primeros auxilios para los vecinos, pues el hospital más cercano está a más de cuarenta cuadras y casi todos los días hay accidentes de cierta gravedad. El barrio ha crecido mucho en los últimos años, por los chicos que nacieron y por los nuevos vecinos que se quedaron sin vivienda y vinieron a parar acá.

Un día, Rubén recibe un llamado de López García, un antiguo compañero de militancia, que ahora ocupa un cargo bastante importante en el gobierno. Concurre a verlo y López García le ofrece una solución rápida a la necesidad del barrio. Él puede conseguir que en un mes se libere una partida para construir la sala y se asigne personal del hospital para atenderla, pero espera a cambio una compensación. Dice que puede 'inflar los números' para que se otorgue un cincuenta por ciento más del dinero necesario y él se queda con esa diferencia. Para hacerlo, solo pide que Rubén haga 'la vista gorda' y hasta ofrece darle 'una parte de la tortita'. Rubén rechaza de entrada esta última sugerencia, pero no rechaza todo el arreglo. Vuelve a su casa pensando que las cosas son así y que, de otro modo, la salita nunca será una realidad. Él sabe que López García va a cumplir lo que promete y que, si quisiera denunciarlo, no tiene modo de probar la oferta deshonesta. También tiene claro que López García es un 'tipo pesado' y una cámara oculta o cualquier artimaña que intente va a terminar con un par de matones en la puerta de su casa. Por otra parte, piensa en los pibes del barrio, en las embarazadas, en los viejos... y recuerda que todos tienen muchas expectativas de su entrevista con López García. A medida que se acerca al barrio, las dudas crecen más ¿Qué debe hacer?

\section{Presentación, análisis y discusión de los argumentos de los jóvenes frente al dilema}

Antes de comenzar esta sección es interesante señalar que el antagonismo entre la "organización barrial" independiente y la política partidaria se presenta desde el enunciado mismo del dilema, reflejando como un leitmotiv una representación social hegemónica de la política propia de la década de 90. Esta fue el correlato discursivo de la aplicación de las políticas neoliberales y la intensificación de los procesos de globalización, a su vez ligados en un plano global a la crisis de las ideologías y las identidades históricas (Carretero, 2007) y a la crisis de representación de la política 
(Touraine, 1997). Ello se cristalizó en la pérdida de credibilidad de la política y de los políticos de modo integral y sin mayores diferenciaciones entre ellos, dentro de una interpretación moral que restringía la comprensión ético-política (Scavino, 1999), centrada en la corrupción como causa de la crisis.

De modo que a primera vista podría objetarse que la propia herramienta que utilizamos para el estudio porta un sesgo moral antipolítico, o en el mejor de los casos "contrademocrático" (Rosanvallon, 2006), ya que el 'bien común' se ubica del lado de quienes no son intrínsecamente ni explícitamente políticos (militantes o funcionarios del gobierno), sino justamente ciudadanos de a pie diferenciados de los políticos, vecinos del barrio nucleados en una 'organización social' cuya identidad se presenta para ellos como no 'política'. Sin embargo, es justamente esta tensión entre la política y la ciudadanía -que aquí reinterpretamos como entre la política y lo político- expresada como autoevidente, lo que le da su singular riqueza a este dilema como herramienta de debate, ya que invita a interrogar la vigencia de un sentido común dominante por más de una década de cara a un nuevo ciclo de rehabilitación de la política. En tal sentido, es una herramienta apta para indagar si la matriz antipolítica sigue estando presente de modo explícito y/o subyacente en las representaciones de los jóvenes de esta generación, si, por el contrario, ya está obsoleta en virtud de los cambios operados, o si convive ambivalentemente en sus modos de pensar/sentir/actuar la política.

Al discutir el dilema, pudimos establecer de modo esquemático dos grandes grupos de valores enfrentados. Uno es el detentado por quienes sostienen que no hay que aceptar el cohecho ofrecido como atajo por el amigo de Rubén para hacer la salita, y dentro de este primer grupo se reivindica "la dignidad" y "la autonomía" (del barrio). El otro es el de los que creen que sí hay que aceptar la propuesta y darle al barrio lo antes posible la salita, siendo los valores centrales "el pragmatismo" y lo que llamaremos "resignación activa" -ya que es puesta al servicio de facilitar una acción en lo inmediato.

Estas dos posiciones, que analizaremos a través de las voces de nuestros entrevistados, dan cuenta sobre todo y más allá de la situación planteada, de dos modalidades distintas de interpretación de la realidad social y del rol que se le otorga a la política como herramienta capaz de dar respuesta a las necesidades básicas de los ciudadanos y la comunidad, encuadrado en la idea del 'bien común'. Y a su vez, ello tiene relación con la agencia que se atribuye en términos de pasividad o actividad, al individuo (en este caso, Rubén) como individuo-sí-mismo en el rol de decisor con poder sobre el grupo, y a los vecinos como colectivo-nosotros en tanto agentes y protagonistas de la construcción de lo común, el barrio.

En base a ello y para comenzar, hemos adoptado el esquema propuesto por Ruiz Silva (2009) para elaborar una categorización esquemática del dilema:

Tabla 1: Categorización de dilema "El barrio puede esperar" 


\begin{tabular}{|c|c|c|c|}
\hline Opciones & $\begin{array}{c}\text { Conjunto de } \\
\text { valores }\end{array}$ & $\begin{array}{l}\text { Sujeto a quien se } \\
\text { atribuye } \\
\text { cada valor }\end{array}$ & Contenido genérico del valor \\
\hline \multirow{2}{*}{$\begin{array}{l}\text { Sí } \\
\text { Aceptar }\end{array}$} & Pragmatismo & Sí-Mismo (Rubén) & $\begin{array}{l}\text { Responder con premura a las } \\
\text { necesidades básicas } \\
\text { del barrio }\end{array}$ \\
\hline & $\begin{array}{l}\text { Resignación } \\
\text { activa }\end{array}$ & Sí-Mismo (Rubén) & $\begin{array}{l}\text { Aceptar los límites de la realidad para } \\
\text { lograr lo que se busca. } \\
\text { Evitar el mal: la enfermedad, la muerte, } \\
\text { etc. }\end{array}$ \\
\hline \multirow{3}{*}{$\begin{array}{l}\text { No } \\
\text { No aceptar }\end{array}$} & $\begin{array}{l}\text { Dignidad } \\
\text { reactiva } \\
\text { (No a la } \\
\text { corrupción) }\end{array}$ & $\begin{array}{l}\text { Sí-mismo (Rubén) / } \\
\text { Nosotros } \\
\text { (el barrio) }\end{array}$ & $\begin{array}{l}\text { Anteponer el proyecto a la urgencia. } \\
\text { Rechazar la corrupción, valorar los } \\
\text { medios y no solo los fines }\end{array}$ \\
\hline & $\begin{array}{l}\text { Dignidad } \\
\text { positiva } \\
\text { (Respeto al } \\
\text { trabajo } \\
\text { comunitario) }\end{array}$ & $\begin{array}{l}\text { Sí-mismo (Rubén) / } \\
\text { Nosotros } \\
\text { (el barrio) }\end{array}$ & $\begin{array}{l}\text { Creer en la obra común, en el trabajo } \\
\text { colectivo. } \\
\text { No ceder a presiones y a la fuerza. } \\
\text { No quedar sometido a la fuerza o al } \\
\text { poder de otros, decidir por sí mismos } \\
\text { el futuro. }\end{array}$ \\
\hline & Autonomía & & \\
\hline
\end{tabular}

Veamos ahora cómo estos valores que esbozamos aquí a grandes trazos cobran vida en los argumentos de los jóvenes, mostrando sus dimensiones y dinámicos matices, además de plantear ejes temáticos específicos.

a) Autonomía/Necesidad:

Comenzaremos por las voces de quienes no aceptan la propuesta, poniendo el centro de la discusión en el peligro que plantea al barrio un pacto con una persona que representa la política facciosa:

Lucila (18): "Yo no aceptaría porque de movida ya están poniendo un montón de condiciones, contra la pared. Tendría una dependencia hacia el chabón y es probable que no sea la última vez que se vean..."

Natalio (17): "Yo no aceptaría el trato ese, porque de alguna manera quedás como pegado. Es algo que no podés retroceder... es complicado... si te metés con gente pesada"

En ambos casos, aceptar condiciones de cohecho aparece como una acción que puede generar compromisos no deseables con personas poco confiables, e implica no solo la pérdida de independencia hoy, en este tema específico, sino la posibilidad de quedar sometidos en el futuro y en otros temas a quienes tienen más fuerza ("gente pesada"). De modo que pactar con políticos corruptos no es simple ("es complicado"), 
puede ser una trampa ("es probable que no sea la última vez que se vean") y se vislumbra como una amenaza directa a la autonomía ("contra la pared").

El criterio que rige esta decisión no es primeramente moral, sino ligado a la preservación y cuidado de la vida y la autonomía; sin embargo, el temor a la pérdida de esta última puede interpretarse como temor al castigo ("quedás como pegado", "no podés retroceder") derivado de la culpa de haber actuado mal ("si te metés con gente pesada").

Ahora bien, lo interesante es que los jóvenes que proponen Sí aceptar el cohecho comparten estas mismas tribulaciones con los que NO, así como su preocupación por el cuidado, pero diferencian su posición al priorizar otros valores en pos de ello:

Francisco (17): "Ponéle que Rubén quiere hacer todo bien y no logra conseguir una salita. Es lo mismo... el tema es la necesidad que tiene la gente que hay ahí, el tema es la necesidad de atender a la gente".

La "necesidad que tiene la gente" es lo primero; luego aparece la necesidad de un sujeto externo "de atender a la gente". De modo que si "la gente" ya es un colectivo genérico que pierde identidad comparado con "los vecinos" (estos vecinos con sus particularidades), a ello se suma que como tal deja de ser protagonista. En la medida en que el verbo y la acción se desplazan a un tercero que -teniendo en cuenta que Francisco es un militante- podría estar refiriendo a un referente político o un dirigente cuya necesidad (la suya, no la de la gente) es "atender a la gente".

En esta línea, donde los vecinos ya no son activos, Corina responde al temor de perder autonomía y "quedar pegado", apoyándose en su propia experiencia biográfica en un barrio de Conurbano Bonaerense:

Corina (19): "Yo digo: buscar una solución por el momento. Quedás pegado pero te tenés que comprometer porque te están dando algo que no tenés de otra manera. Hay muchas cosas así. Suponéte que conseguís un trabajo con militancia: te doy esto y vos venís a la marcha... o trabajás para mí, después venís, te paso a buscar con un micro, pasan listas, si faltaste... ¿qué pasó que no estás viniendo?..."

La entrevistada naturaliza el cohecho como un intercambio más dentro de un tipo de prácticas con las que convive y que -en una expresión ilustrativa de la violencia simbólica (Bourdieu, 1979)- justifica reproduciendo (literalmente y en segunda persona) el discurso que ella misma ha recibido: "te tenés que comprometer porque te están dando algo que no tenés de otra manera". De modo que la dependencia o la pérdida de autonomía no aparecen aquí como sometimiento al poder, sino a la realidad misma; digamos que como un acuerdo legítimo: dar a cambio de lo que se recibe. 
Luego, la participante toma como ejemplo su "trabajo con militancia", pero no para cuestionarlo moralmente, sino para enfatizar que el hecho planteado en el dilema no está fuera de la norma, sino que es precisamente lo ordinario: "hay muchas cosas así". Por lo tanto, pierde su carácter conflictivo y se coloca en un plano pragmático: "buscar una solución por el momento". Algo importante para preguntarnos es qué sucede con la dimensión de la legalidad en esta construcción de lo normal; evidentemente, está ausente o no es demasiado relevante -y sin embargo, es justamente allí donde podría abrirse camino el planteo político.

\section{b) Estado/Ciudadanía:}

Un segundo eje temático que vertebró la discusión es el que problematiza el rol del Estado y la relación con los ciudadanos, mostrando cómo las concepciones sobre este son determinantes para definir la actitud y el posicionamiento de los jóvenes: ¿Cuál es el rol del Estado en la distribución del bien común? ¿Qué se le debe y qué se le puede pedir?

En las respuestas a estas preguntas se conjugan aspectos de diversas concepciones de Estado que toman mayor o menor distancia con la que propone el dilema y que suelen coexistir en las representaciones de los sujetos, no siempre de modo explícito. Es en el análisis donde podemos diferenciarlas y evaluar qué peso asume cada una, considerando al Estado de un modo relacional e interconstituyéndose con otras instancias de lo social (como la sociedad civil o ciudadanía, sus instituciones y organizaciones, sus prácticas instituyentes). Como marco conceptual, tomaremos de otro trabajo (Kriger y Said, 2015) la categorización de cuatro concepciones del Estado, tributarias de distintos posicionamientos político-ideológicos históricos pero vigentes y coexistentes en la actualidad; a saber: a) el Estado neoliberal: el rol integrador es asumido por el mercado, instalando una lógica individual que reduce al Estado y lo exime de promover la creación de vínculos societales entre sujetos, capaces de generar resistencias y disidencias (Martín Barbero, 1987); b) el Estado social: remite al Estado de bienestar moderno, que centraliza las prácticas y sentidos sociales (Ortiz, 2002); c) el Estado inclusivo: una variante más política del Estado social que integra a la sociedad civil, diluyendo el conflicto social en clave neokeynesiana, y d) el Estado en tensión: expresa la relación de fuerzas entre la sociedad civil, compuesta por las clases subalternas organizadas, y la sociedad política, formada por las clases dominantes que detentan la hegemonía, en clave gramsciana.

El dilema utilizado no es, -como dijimos- neutral, sino que presenta la situación desde un contexto en el que prevalecía una concepción neoliberal del Estado, cuyo acceso a los ciudadanos estaba intervenido por políticos corruptos y una dinámica facciosa que socavaba la legitimidad de la representación política. En la discusión del dilema se confrontan también otros modelos y expectativas en torno al Estado: 
Jorge (18): "Yo creo que el Estado se tiene que hacer cargo absolutamente de todos esos problemas, porque después..."

Jorge aspira a una variante de Estado social que se polariza hacia una modalidad de hiperbenefactor ("se tiene que hacer cargo absolutamente de todos esos problemas"), aunque más para evitar un mal mayor que para asegurar el bien común ("porque después..."). Esto podría vincularse a la experiencia de la crisis de 2001 y la ruptura del enlazamiento social -muy presente en la biografía y en la historia familiar de nuestros entrevistados- que, frente a la experiencia de lo que el supuesto 'abandono' del Estado generó, supone lo inverso en la forma de una presencia omnipotente y protectora, como si solo él pudiera salvar a la sociedad de la catástrofe que la amenaza. Nótese que al agudizarse el protagonismo del Estado, se convierte en un actor externo y poderoso pero que no sale de adentro, sino que aparece por fuera de la ciudadanía, que queda relegada a un papel pasivo.

Veamos otro caso:

Lucila (18): "El Estado se tiene que hacer cargo de las cosas básicas, yo no digo que se tiene que hacer cargo de un berretín tuyo, de un helado. Pero, juna salita! Como un colegio, como este, por ejemplo: siete años buscando los sueldos, no se lo dieron todavía, pero se lo van a dar"

Lucila tiene una visión más moderada, inclinándose por un Estado inclusivo de tipo benefactor, que asegure las necesidades básicas: salud y educación, especialmente. A diferencia de ella, Sofía quiere prescindir del Estado:

Sofía (17): "Yo no veo bien que el Estado siempre va a tener que cubrir, no estoy de acuerdo con pedir siempre al Estado, esa forma fácil... Acá mirá: vuelven a la escuela, le decís: hay marcha y se vuelven todos a sus casas. También se cansan, ya van siete años, siempre lo mismo... que vamos y cortamos una plaza. ¿Qué vamos a lograr cortando una plaza?"

Ella dice no ver bien que el Estado tenga que "cubrir", rechaza pedirle "siempre" -y reitera el "siempre"- como si expresara su contraposición con un "nunca" implícito, el de la inacción de los ciudadanos, como si el "cubrir" del Estado contribuyera productivamente a generar esos ciudadanos no cubiertos. Hay un reproche moral al facilismo, pero también podemos escuchar, tras ese pedido de retiro de interpelación, una demanda de acción política a los ciudadanos y de dignidad activa. En este sentido, propone algo más cercano al tipo de Estado en tensión, matizado por la fatiga de quien ya ha vivido el abandono y prefiere no pedir y no esperar; no le habla a él porque de hecho no está. Interpela en cambio a los suyos, a la sociedad civil conformada por quienes siguen desgastándose en la expectativa de recibir, ese nosotros del que forma parte ("¿qué vamos a lograr cortando una plaza?"). Se refiere a su escuela y a los siete 
años de protestas y manifestaciones públicas pidiendo que les paguen el sueldo a los docentes, ${ }^{4}$ donde dejar de ir a clase para ir a la marcha o "cortar una plaza" terminan siendo acciones vacías de sentido, repetidas hasta el hastío y la pereza.

El argumento de Santiago tampoco espera nada del Estado y propone salir del dilema para buscar "otro recurso" en una multinacional:

Santiago (17): "Buscaría otro recurso... fuera del dilema, otros lugares: las multinacionales. Muchas ayudan a la gente, y puede haber algo... Lo digo porque en un barrio que estoy cerca yo, los Pimpinela fundaron y va la gente a comer..."

Sin embargo, su propuesta no interpela a la sociedad civil, lo que implicaría una salida hacia lo político provocada por su desconfianza de la política establecida, sino al Mercado ("las multinacionales"), precisamente esa instancia que -de acuerdo a una lógica neoliberal muy extendida a finales de siglo XX, cuyo fracaso se hizo evidente en la última década con la explosión global de la crisis (aunque subyace con fuerza en las representaciones sociales)- habría sustituido al Estado en su rol integrador asumiendo un papel protagónico en la organización de las relaciones sociales. Nótese que el entrevistado confunde una fundación de carácter civil (la de "los Pimpinela") con una "multinacional", lo que podría ser consecuencia de su visión excesivamente simplificada de lo social, que termina borrando las instancias ciudadanas y/o populares, y concentrando la capacidad de conseguir las cosas necesarias en los que tienen poder (en este caso, económico). Un dato interesante es que Santiago, como muchos de los jóvenes que participaron del estudio, es beneficiario de una beca estatal para terminar sus estudios secundarios ("beca joven") que recibe a través de procedimientos directos y sin la mediación de contactos políticos; y sin embargo, este hecho aparece eclipsado por la experiencia territorial ("un barrio que estoy cerca yo"), donde perviven las lógicas clientelares.

\section{c) Más acá/más allá del dilema moral}

En algunos momentos de la discusión con los jóvenes, notamos que la presión por tomar una posición que nunca es la deseada y siempre es problemática -ya que las dos alternativas disponibles encarnan valores en conflicto dentro de ellos- puede llevar a algunos a intentar una fuga del dilema. Se cuestiona que ofrezcan realmente una disyuntiva y se comienzan a generar alternativas o "terceras vías" para relativizar el carácter inexorable (trágico) de su resolución. Veamos algunos ejemplos, empezando por la protesta e interrogación de Lucila, que abre el camino:

\footnotetext{
${ }^{4}$ Este diálogo se tomó del trabajo en un Bachillerato Popular, cuya agrupación durante muchos años sostuvo la lucha por títulos oficiales y sueldos a los docentes, lo cual finalmente se logró en los últimos años.
} 
Lucila (18): "¡Se puede buscar por otro lado! ¿iPor qué es la única salida para la salita!?".

En otros casos, frente a la imposibilidad de escapar del dilema, se produce un desdoblamiento del sí-mismo del tipo: pienso de un modo pero actúo de otro, como un singular sacrificio de una parte de sí (la más ligada al yo, a los valores, a la identidad y al proyecto deseados) en pos de responder pragmáticamente a una realidad implacable:

Leo (18): "Acepto esto pero sigo pensando igual, me hago cargo de lo que hice (no dejo los ideales a un lado), no lo hice por mi beneficio. Encima hacés eso y te dan la salita enseguida, si tenés que esperar del gobierno... van a pasar años".

Este joven "acepta" resignado, pero negando la autenticidad o la verdad de su acción en un plano subjetivo ("no dejo los ideales a un lado"). No legitima hacer "eso", pero lo justifica como medio para lograr la salita, un sacrificio moral donde el cohecho se transforma en virtud ("me hago cargo de lo que hice"), dando lugar a lo que llamamos aquí "resignación activa". A eso responde una compañera que se opone y para quien el desdoblamiento no salva de la contradicción:

Carla (18): "No por eso él va a sacrificar todo lo que hizo... y va a hacer una transa con este tipo".

Para ella, que responde desde una dignidad reactiva, el sacrificio no es tal, sino "una transa" -además, "con este tipo") que no solo afecta subjetivamente los valores de Rubén, sino que desvirtúa las acciones objetivas y la historia ("todo lo que hizo").

Rocío se sitúa entre las dos últimas posiciones:

Rocío (17): "Creo que habría que organizarse de otra manera entre los vecinos. Aceptar la salita y por otro lado te vas armando otra salita"

La entrevistada propone un desdoblamiento pero de tipo colectivo, donde la resignación activa deviene en propuesta de organización barrial aunque con un planteo muy rudimentario para ser viable.

Más o menos torpes, más o menos logrados, los intentos de fuga son estrategias especialmente interesantes para nuestro abordaje, porque al tantear los límites del dilema moral, pueden implicar el comienzo de una problematización más compleja del conflicto, que el dilema -en tanto constructo instrumental- necesariamente simplifica. Escapar a la disyuntiva moral implica aspirar a expandir el horizonte de posibilidades, pero requiere recursos y herramientas cognitivas para lograrlo. Cuando falla, se limita a la negación o postergación del conflicto, pero sí se logra incorporar la dimensión del 
pensamiento ético-político. Algo de este orden se produce en la discusión tras llegar al punto de mayor condicionamiento del grupo a favor de aceptar el cohecho, que aparece como un mal menor frente al bien absoluto de la vida que debe ser salvada.

Ignacio (17): "Hay un montón de gente que roba y sin embargo no hace. Así que yo creo que en este caso habría que conformarse porque hay una realidad: la salita se necesita, jes algo urgente!, ¡la salita es una necesidad urgente! Yo sé que no es la mejor solución, pero a veces en la vida hay que resignarse, o sea, todas estas cosas no las vamos a poder cambiar..."

Las palabras del participante ilustran muy bien cómo funciona la resignación activa y nos ofrece dos tópicos frecuentes del discurso antipolítico que la justifican: la normalización del robo y la excepcionalidad del hacer en la política ("Hay un montón de gente que roba y sin embargo no hace"). Esta visión conlleva a mirar la realidad social como un hecho dado, único e inalterable, por fuera del alcance de la acción humana ("habría que conformarse porque hay una realidad", "todas estas cosas no las vamos a poder cambiar"), que obligaría a quien está atento a las necesidades de las personas, a resignar en función de permitir que se haga algo ("Yo sé que no es la mejor solución, pero a veces en la vida hay que resignarse...") De esto modo, realiza un sacrificio moral individual donde la resignación aparece como virtud porque habilita la acción y también se presenta como una respuesta ética al requerimiento de la comunidad. Es entonces cuando la respuesta de Juan viene a desafiar el dilema y a ir más allá de la interpelación moral:

Juan (18): "¿Pero la sala se necesita ya? ¿En qué sentido? Porque si estamos hablando de hacer una salita, no se hace de un día para el otro, ino es que la traes y ya está! Hay que hacer una licitación, hay que comprar el lugar, hay que poner la plata, tiene que "salir" la plata... No se hace de un día para el otro, no se hace de un día para el otro"

Es bien interesante lo que hace Juan, precisamente porque lo que interroga es aquello que aparecía como por fuera de la discusión, el núcleo "real" que constituía el punto de apoyo para el consenso implícito o sentido común del grupo: la necesidad impostergable de la salita ("¿Pero la sala se necesita ya? ¿En qué sentido?..."). En la medida en que el entrevistado pone en duda e incluso niega la verdad fáctica en que se apoya ese piso común en que estaban parados -tres veces dice: "No se hace de un día para el otro"-, la discusión sobrepasa el terreno moral e invita no a resolver el dilema, sino a preguntarse por las condiciones que lo hacen posible ("Porque si estamos hablando de hacer una salita, no se hace de un día para el otro, no es que la traés y ya está!"), por la "realidad" instalada en la trama de los hechos sociales que cobra carácter social y construido ("Hay que hacer una licitación, hay que comprar el lugar, hay que poner la plata, tiene que "salir" la plata"). 
En toda esta argumentación lo más relevante es el efecto producido por traer el tiempo al dilema, es decir: mostrar que más allá del dilema moral no se trata de "conseguir" la salita, sino de hacerla, de habilitar un proceso que sucede en el tiempo cronológico. Porque en el reconocimiento de la temporalidad de la acción social se revela la relación constitutiva entre historicidad y política: las personas (los vecinos) hacemos lo proyectos colectivos (el barrio) en/a lo largo del tiempo, por eso Carla se suma:

Carla (17): "Es que... es tan sólida la realidad esa que no sirve para nada..."

En efecto, la urgencia funciona como una argumentación altamente destructiva en términos políticos. Al no dejar margen para la el desarrollo en el tiempo de la acción histórica, los hechos parecen imponerse por su peso, ajenos a la producción humana. Inversamente, al reinstalar el tiempo y la historia, se rehabilita el proyecto y la política:

Serena (18): "Para mí todo se puede cambiar, las sociedades han cambiado muchísimo en los años, pensando en la revolución francesa es posible cambiar. Ahora, ¿qué haría frente a este dilema? Yo no aceptaría, yo creo propondría un intercambio en un espacio político, siempre va a haber algo pequeño y en algún punto tiene que empezar"

\section{Reflexiones finales}

A lo largo de este artículo hemos analizado los modos en que las concepciones, emociones, valoraciones y actitudes respecto de la política y lo político de los jóvenes que han participado de nuestro estudio, intervienen en su posicionamiento psicológico (Harré, 2012) frente a una situación de conflicto planteada por el dilema moral. Queremos destacar la relevancia que tiene el trabajo grupal y la deliberación con pares en la construcción de argumentaciones, como práctica clave de interacción y negociación dialógica (Bruner, 1990) para la construcción democrática del mundo social, que implica la autocalificación de los sujetos como ciudadanos reflexivos, vale decir: conscientes de su capacidad de transformación de sí y de su mundo.

En nuestro trabajo con este dilema encontramos, en primer lugar, que las dos posiciones opuestas frente al dilema (Sí o No), presentan, sin embargo, un acuerdo moral entre los sujetos que las detentan acerca de qué es lo bueno y lo malo para el barrio/la comunidad. Todos los participantes adhieren centralmente a la necesidad de hacer la salita, que es reconocida como objeto al que se orienta la acción y como "bien común". Es importante señalar que en una y otra alternativa las posiciones cambian en relación con la interpretación de la situación y, sobre todo, varía la autocalificación de los entrevistados y la percepción de su propia potencia como sujetos sociales (en identificación con "los vecinos"), capaces de cambiar y construir la realidad (en este caso, de "el barrio"). Sin embargo, como ya dijimos, estas posiciones no son totalmente 
antagónicas, sino que coinciden en cuanto a la valoración moral de lo que está en juego: el positivo (lo bueno) es conseguir "la salita", y el negativo (lo malo) es la corrupción política. Las diferencias aparecen no en relación con las necesidades del barrio (el bien común), sino a qué medios están dispuestos a aceptar para lograr este fin. Es justamente en este punto donde se pone en juego la percepción del mundo social, que puede aparecer como "la realidad" dura a la que Rubén y los vecinos deben amoldarse, o como una construcción social que ellos podrían intervenir y modificar. Nada menos que la medida de su horizonte de la política, cerrado o abierto. De modo que la diferencia entre las dos posiciones que plantea el dilema conducen al problema de cuáles son las prácticas legítimas -pero no en un plano ideal, sino concreto, en situación- para lograr el "bien común", y a cómo se relacionan lo deseado y lo posible, lo imaginado y lo viable, en la experiencia concreta y cotidiana de lo comunitario como proyecto de vida (en marcha). En última instancia, este dilema plantea una diferencia que no escinde el "nosotros" respecto del fin buscado, sino de la legitimidad de los medios para lograrlos sin traicionar lo fundamental del proyecto en el cual lo común adquiere su sentido y es el "nosotros" que se actualiza; vale decir: lo político.

Las diferencias se plantean entonces no en torno a lo que deben conseguir, sino a cómo deben conseguirlo, lo cual nos lleva a interrogarnos por las virtudes y su importancia como eslabón entre una psicología moral y una política, cuando el horizonte es la autonomía, tal como lo expresa Fernández Cid:

El tema de las virtudes se torna complejo debido a que la persona no es simplemente un "aplicador" de normas morales. El sujeto se vuelve capaz de gobernarse a sí mismo regulando su propia autonomía, al mismo tiempo que participa en un proceso histórico y socio-cultural descubriendo nuevas normas. Por tanto, en ocasiones, la persona recurrirá a normas ya conocidas $y$, en otras, determinará normas ad hoc que surgen de la capacidad de su evaluación ante una situación específica. En ambos casos lo relevante es la autonomía, como un elemento personal que implica la libertad de poder asumir ciertas decisiones y actuar en pos de ellas (Fernández Cid , 2013: 46).

Otra muestra de la politicidad del dilema utilizado está dada en que si bien pone en evidencia un malestar moral respecto de los políticos socialmente muy extendido en el contexto de nuestro estudio, no plantea una actitud ciudadana pasiva, sino activa en una nueva clave, que hemos vinculado con lo que Rosanvallon (2006) denomina "contrademocrática" y cuya figura soberana es el pueblo que vigila, que custodia, que veta de modo directo, imponiéndose sobre la figura del viejo pueblo elector. Teniendo en cuenta esto, quienes frente a la disyuntiva planteada se inclinan por el NO (es decir: porque Rubén no acepte la propuesta que le hace su excompañero de militancia y ahora político de oficio, de montar la salita con su "ayuda") rechazan una práctica de la política real -y facciosa-, pero justamente mientras reivindican lo político como acción 
destituyente y al mismo tiempo permanentemente instituyente del orden social. $\mathrm{Y}$ quienes se inclinan por el SÍ (o sea: porque Rubén "transe" con su amigo corrupto) son aquellos que, descreídos de la capacidad transformadora de la política tanto como de la de los ciudadanos para luchar contra la corrupción instaurada por ella, creen en su poder fáctico y descreen de lo político en este plano, por lo cual optan por ser pragmáticos, adoptando lo que hemos llamado una resignación activa.

Por último, queremos destacar e invitar a seguir profundizando en otros estudios el particular hallazgo referido a la relación entre tiempo y política, ya que el dilema es llevado a sus límites cuando uno de los jóvenes cuestiona la urgencia de la salita, que se presentaba como autoevidente, sin negar por ello su importancia y necesidad pero colocándola dentro de un proceso más vasto de acción colectiva que implica un desarrollo en el tiempo. En esta argumentación, se insinúa la crucialidad que tiene la temporalidad para la construcción y sostenimiento de un proyecto en el marco de una búsqueda irrenunciable de autonomía, que abre los horizontes de acción más allá del pragmatismo y de la modalidad singular que hemos llamado aquí "resignación activa" hacia el ejercicio de una vida en común que aspira en cambio a una "dignidad activa".

\section{Bibliografía:}

Aguiló, V. \& Wahren, J. (2013). Educación Popular y Movimientos Sociales: Los Bachilleratos Populares como 'Campos de Experimentación Social'. Ponencia presentada en: X Jornadas de Sociología. Universidad de Buenos Aires (UBA), Buenos Aires.

Bourdieu, P. (1979). La distinction. Critique sociale du Jugement. París: Minuit

Bruner, J. (1990): Actos de significado. Más allá de la revolución cognitiva. Madrid: Alianza, 1991.

Carretero, M. (2007): Documentos de identidad. La construcción de la memoria histórica en un mundo global. Buenos Aires: Paidós.

Castorina, J. \& Faigenbaum, G. (2003). The epistemological Meaning of Constraints in the Development of Domain Knowledge. Theory \& Psychology, 12 (3), 315-334.

Chaves, M. (comp.) (2009). Estudio sobre Juventudes en Argentina. Hacia un estado del Arte 2007. La Plata: Editorial Universidad de La Plata.

Espósito, R. (1988): Categorías de lo impolítico. Buenos Aires: Katz.

Fernández-Cid, H. (2014): Construcción de la Identidad Ciudadana en jóvenes: Una aproximación a la Activación Emocional, los Relatos de Ciudadanía y los Valores puestos en juego en el Espacio Socio-Cultural (Tesis doctoral). Dirección: D. Alberto Rosa Rivero, codirección: D. ${ }^{\text {ra }}$ Miriam Kriger. Facultad Latinoamericana de Ciencias Sociales, Buenos Aires. 
Harré, R. (2012). Positioning Theory: Moral Dimensions of Socio-Cultural Psychology. En J. Valsiner (Ed.) The Oxford Handbook of Culture and Psychology (pp. 191-206). Oxford: Oxford University Press.

Kohlberg, L. (1984). Essays in Moral Development. The Psychology of Moral Development. San Francisco, Harper and Row [Ed. cast.: Psicología del desarrollo moral. Bilbao Descleé de Brouwer, 1992]

Kriger, M. (2007). Historia, Identidad y Proyecto: un estudio de las representaciones de jóvenes argentinos sobre el pasado, presente y futuro de su nación (Tesis doctoral) Dirección: Dr. Mario Carretero. Facultad Latinoamericana de Ciencias Sociales, Buenos Aires.

Kriger, M. (2010). Jóvenes de escarapelas tomar: Escolaridad, enseñanza de la historia y formación política en la Argentina post 2001. La Plata: EDULP

Kriger, M. (2011). La enseñanza de la historia reciente como herramienta clave de la educación política: Narrativas escolares y memorias sociales del pasado dictatorial argentino en las representaciones de jóvenes estudiantes de la Ciudad de Buenos Aires y conurbano (2010-11). Persona y Sociedad, 25 (3), 29-52.

Kriger, M. (2012). La invención de la juventud, entre la muerte de las naciones y su resurrección. En Kriger, M. (Comp.). Juventudes en América Latina: abordajes multidisciplinares sobre identidades, culturas y políticas del siglo XX al siglo XXI. (pp. 1-27). Buenos Aires: CAICYT CONICET.

Kriger, M. (2013). Reflexiones acerca de la despolitización y la politización juvenil en la Argentina, entre la desestructuración y la reestructuración del Estado Nacional. Dossier: Juventudes políticas, $6^{\circ}$ título de la colección Sociales en debate, Facultad de Ciencias Sociales, Universidad de Buenos Aires. Argentina.

Kriger, M. (2014). Politización juvenil en las naciones contemporáneas. El caso argentino. Revista Latinoamericana de Ciencias Sociales, Niñez y Juventud, 12 (2), 583-596.

Kriger, M. \& Bruno, D. (2013). Youth and Politics in the Argentine Context: Belief, Assessment, Disposition, and Political Practice among Young Students. C@ahiers de Psychologie Politique, 22.

Kriger, M. \& Daiban, C. (2015). Del ideal del ciudadano al ciudadano en-situación: Un estudio sobre los modelos de ciudadanía y los posicionamientos subjetivos de jóvenes ciudadanos en la Argentina actual (Buenos Aires y Conurbano, 2011-13). Revista Folios. UPN, Bogotá.

Kriger, M. \& Dukuen, J. (2014). La política como deber. Un estudio sobre las disposiciones políticas de estudiantes argentinos de clases altas (Buenos Aires, 2011-2013). Revista Persona y Sociedad, 28 (2), 59-84.

Kriger, M. \& Fernández-Cid, H. (Noviembre, 2011). Los Jóvenes y la Construcción del "Ciudadano Ideal". Una Aproximación a las Acciones y Relatos de Ciudadanía de Jóvenes Escolarizados de C.A.B.A y Pcia de Buenos Aires. Ponencia presentada en el 
III Congreso Internacional de Investigación de la Facultad de Psicología de la Universidad Nacional de La Plata. La Plata. Argentina.

Kriger, M. y Said, S. (2015). Subjetivación política en Bachilleratos Populares: Concepciones acerca del Estado y actitudes hacia la participación política entre estudiantes de la Ciudad de Buenos Aires. XI Jornadas de Sociología, Facultad de Ciencias Sociales, Universidad de Buenos Aires.

Kropff, L. \& Núñez, P. (2009). Eje Acción, participación, opciones y estrategias políticas. En M. Chaves (ed.) Juventudes en Argentina. Hacia un estado del arte/2007. La Plata: Editorial Universidad de la Plata.

Lefort, C. (1992/2007). El arte de escribir y lo político. Barcelona: Herder.

Martín Barbero, J. (1987): De los medios a las mediaciones: comunicación, cultura y hegemonía. Santa Fe de Bogotá: Convenio Andrés Bello.

Milstein, D. (2009): La Nación en la escuela. Nuevas y viejas tensiones políticas. Buenos Aires: Miño y Dávila.

Muñoz, M. A. (2004): Los discursos de la desocupación y la pobreza, las organizaciones de desocupados y la esfera político estatal. En Laboratorio/n line: Revista de Estudios Sobre Cambio Social, del Instituto de Investigaciones Gino Germani, Facultad de Ciencias Sociales (UBA), 2004.

Ortiz, R. (2002). Globalización/Mundialización. En Altamirano, C. (Comp.): Términos críticos de Sociología de la Cultura. Buenos Aires: Paidós.

Perez, G. \& Natalucci, A. (2012). El kirchnerismo como problema sociológico. En Perez G. \& Natalucci, A. (Comps.): Vamos las bandas. Organizaciones y militancia kirchnerista (pp. 7-26). Buenos Aires: Trilce.

Rosanvallon, P. (2006). La contrademocracia: La política en la era de la desconfianza. Buenos Aires: Manantial.

Ruiz Silva, A. (2009). La nación en los márgenes. Estudio de los elementos de carácter representacional, moral y político en relatos de nación de jóvenes de últimos grados de secundaria, de una escuela pública, en el conurbano bonaerense. (Tesis Doctoral) Dirección: Dr. Mario Carretero. Facultad Latinoamericana de Ciencias Sociales, Buenos Aires.

Scavino, D. (1999). La era de la desolación. Buenos Aires: Manantial.

Siede, I. Helman, M. \& Micó, G. (2001). Formación ética y ciudadana Propuestas de enseñanza para segundo ciclo. Dirección de Currícula Gobierno de la Ciudad de Buenos Aires. Argentina.

Touraine, A. (1997). ¿Podremos vivir juntos? Iguales y diferentes. Madrid: PPC.

Vázquez, M. (2013). En torno a la construcción de la juventud como causa pública durante el kirchnerismo: principios de adhesión, participación y reconocimiento. Revista Argentina de Estudios de Juventud, (7), pp. 27-36. 
De Prácticas y discursos/ Universidad Nacional del Nordeste/ Centro de Estudios Sociales

Vommaro, P. (2013). Las relaciones entre juventudes y políticas en la América Latina contemporánea: una aproximación desde los movimientos estudiantiles. Sociedad, (32), pp. 127-144. 